\title{
Discrete element modelling of a laboratory static test on welded wire mesh
}

\author{
E Karampinos University of Toronto, Canada \\ B Baek University of Toronto, Canada \\ J Hadjigeorgiou University of Toronto, Canada
}

\begin{abstract}
Although the use of steel mesh is an integral part of the ground support arsenal for underground mines, there are limited design guidelines available. In effect, the role of mesh is not explicitly accounted for in design. The selection of a particular type of mesh is often based on empirical knowledge and field observations. In this context, the use of laboratory testing rigs have been useful, in that they provide the means for a comparative analysis of performance between different types of mesh, for example weld mesh and chain-link under static and dynamic loading. It is noted, however, that for practical reasons the majority of the testing rigs only investigate a single loading mechanism and under specific boundary conditions. The challenge has been how to investigate different loading conditions and to eventually use this knowledge in the design of mesh for underground excavations. The use of numerical modelling can eventually provide a more robust design tool.

This paper presents a numerical investigation of the mechanical behaviour of the welded wire mesh using the discrete element method (DEM). As a first step, the focus was on the use of the DEM to reproduce results from laboratory testing rigs of mesh subjected to static load through a loading plate. This paper describes ongoing work to capture the performance of welded mesh. Structural elements in the 3D DEM were calibrated to successfully capture the mechanical behaviour of the welded wire mesh as reported in the tests. The 3D DEM model explicitly simulates the interaction between the loading plate, the testing frame and the surface support elements. The model successfully reproduced the observed stress redistribution on the steel wires, the measured displacement and the failure mechanism of the mesh for the examined test configuration. The proposed technique can be extended to investigate the performance of the welded wire mesh under different loading conditions.
\end{abstract}

Keywords: ground support, welded wire mesh, discrete element method

\section{Introduction}

Steel mesh is used to retain the ground and provide confinement to the rock mass surrounding excavations in rock. In this respect, it is an integral and critical part of ground support. Nevertheless, it is not explicitly taken into account in the design of ground support. This is probably due to the difficulties in quantifying the load, capacity and interaction between the various components of ground support and reinforcement.

The behaviour of steel wire mesh under loading can be examined through analytical, empirical and numerical methods, as well as laboratory tests. Analytical methods can contribute towards the understanding of the interaction between the parameters that control the mechanical behaviour of mesh. Coates (1981) developed an analytical equation for the maximum tensile force that single mesh wires can withstand as a function of the reinforcement spacing, the vertical pressure and the mesh sag. Tannant (1995) presented analytical equations to identify the load capacity of welded wire mesh based on assumptions of uniform and point loading of a single wire fixed at both ends. However, these approaches are not used for ground support design. 
In practice, ground support design is primarily based on empirical methods and past experience. In this regard, the Q-system (Barton et al. 1974) is broadly used to characterise and classify the rock mass. The ground support design chart developed by Grimstad and Barton (1993) uses the Q-system to provide ground support recommendations. Although in the original design chart (Barton et al. 1974) there were recommendations for the use of mesh, these were dropped in the subsequent versions of the Q-system (Grimstad \& Barton 1993) in favour of fibre-reinforced shotcrete. This is a reflection of tunnelling practice where mesh is not widely used. In a mining context, Potvin and Hadjigeorgiou (2016) developed ground support guidelines based on data from 65 mines in Australia and Canada that include the use of mesh. However, these guidelines are meant to be used as a first pass design at the early stages, such as during the feasibility stage and the early mine development.

Laboratory tests can provide quantitative information on the performance of mesh under different static and impact conditions. For practical reasons, the laboratory testing rigs can only investigate limited loading mechanisms and boundary conditions. Therefore, it is difficult to extrapolate these results to actual field conditions.

The use of numerical modelling to investigate the behaviour of mesh is an attractive proposition. However, there are significant challenges in implementing mesh in numerical models, let alone representing field conditions. This paper reports on work towards reproducing the mechanical behaviour of welded wire steel under controlled laboratory conditions using the 3D distinct element method (DEM).

\section{Performance of welded wire mesh in laboratory tests}

One of the earliest full-scale static testing rigs for testing mesh was reported by Ortlepp (1983). In this configuration, the mesh was attached to a testing frame through a peripheral clamping arrangement, and the load was applied at the centre of the mesh through four steel plates. Different degrees of stress concentration and impairment of material properties co-existed, depending on the type of cross-over (i.e. welded, woven, knotted or linked).

Tannant (1995) used a full-scale static testing rig of welded steel wire mesh to investigate different diamond and square bolting patterns on three different wire diameters. Higher peak load capacities and stiffer responses were observed with thicker steel wires, while the diamond bolting pattern gave the stiffest response. A significant drop in the load was caused by failure of a mesh wire, while smaller drops in the load were generally associated with the slippage of the mesh underneath the reinforcement plates.

Thompson et al. (1999) investigated the performance of welded wire mesh held down on a concrete floor using four square steel plates using bolts. Several mesh, bolt and loading configurations were tested resulting in different load-displacement responses. It was noted that as the bolt spacing increased, the stiffness decreased. Slip of the mesh at the plates also contributed to the reduction of stiffness of the loading response. Dolinar (2006) investigated the load and stiffness characteristics of welded wire steel mesh. The mesh was constrained using plates and round-edge plate was used to apply the load. The conditions on the plate, including the bolt torque, the plate size and the load surface, affect the yield load and the stiffness of the mesh. Morton et al. (2007) used a large-scale static testing rig of mesh with two distinct types of boundary constraints - lacing and shackle. A steel plate was used to apply a load to the centre of the mesh.

Laboratory testing can provide a good indication of the relative performance of mesh under a given set of loading and constraining conditions. However, it is still difficult to extrapolate the results of these tests to predict in situ performance. The use of numerical modelling can eventually provide a more flexible design tool. However, this would require further development of appropriate numerical tools and a demonstration that it can reproduce observed behaviour under a range of loading conditions. 


\section{Continuum and discontinuum modelling of ground support}

In general, the presence of mesh as part of a ground support system is not taken into account in numerical models. In the limited numerical modelling investigations reported in the technical literature, the focus has been on the simulation of laboratory tests using contunuum modelling approaches. Shan et al. (2014) used FLAC3D (Itasca Consulting Group Inc. 2012) to simulate the performance of welded steel mesh in pull conditions under laboratory tests. In this numerical experiment, the mesh was modelled as a collection of beam structural elements with links corresponding to the weld points in the mesh. The input parameters used in the model were determined from laboratory tests on individual wires. A good match was obtained between the load-displacement curves derived from the laboratory tests and the numerical model. The deformation of welded mesh under different loading conditions has been modelled by Roth et al. (2014) using pile structural elements in FLAC3D. Gadde et al. (2006) also used pile elements in FLAC3D to model the behaviour of welded wire mesh reporting a good match to load-displacement curves from laboratory results. It was also possible to identify areas of higher modelled load on the steel. Morton et al. (2007) used a continuum finite element non-linear model to reproduce the load-displacement curve from a laboratory test loading a chain-link mesh.

In the reported continuum-based models, there was limited information on how the load transfer was reproduced on the steel wires during the different loading stages and failure mechanisms. Ideally, a complete representation of the mechanical behaviour of the mesh should capture both the load redistribution on the steel wires and the failure mechanism.

The choice of an appropriate numerical method for ground support is based on identifying the failure mechanism of the rock mass and the ground support (Lorig \& Varona 2013). However, continuum numerical methods cannot explicitly reproduce the non-linear anisotropic behaviour of the rock. Discontinuum modelling approaches can better simulate the structurally controlled instabilities and the failure mechanisms in the rock mass. The DEM can better capture the mechanics of the rock mass behaviour and explicitly model the interaction between the rock mass and the ground support elements. However, limited work has been done on the simulation of the behaviour of mesh using the DEM. DEM applications have focused on modelling mesh using spherical particles (Bertrand et al. 2008; Thoeni et al. 2014). However, these approaches cannot be extended to model ground support systems. This paper focuses on reproducing the mechanical behaviour of mesh using structural elements in the 3D DEM.

\section{Application of the 3D DEM for the simulation of a laboratory static test in mesh}

\subsection{Problem definition}

The first step in this work was to investigate whether the use of structural elements in a 3D DEM could emulate a simple laboratory experiment of applying a static load on a mesh. The static test configuration reported by Morton (2009) was selected as it used a single loading mechanism without any interaction between rockbolts and plates (Figure 1). The load was applied on a $300 \times 300 \mathrm{~mm}$ square steel plate at the centre of the mesh sample. The $1.3 \times 1.3 \mathrm{~m}$ long mesh was connected to the metallic sample frame by a series of fixed steel ' $D$ shackles' that provided a rigid boundary condition to the mesh. The diameter of the steel wires was $5.6 \mathrm{~mm}$, and the wire spacing formed a $100 \times 100 \mathrm{~mm}$ grid.

In a series of experiments, Morton (2009) observed the following mechanisms: tensile failure of the wire, failure of the wire at the heat affected zone (HAZ), and weld failure. Tensile failure occurred when the weld strength was greater than the axial strength of the wire. The weld usually failed in shear. Failure of the wire through the HAZ occurred due to the reduction in the cross-sectional area of the wire. Similar load-displacement curves were observed irrespective of the failure mechanisms with mesh failure always localised at the boundary of the testing rig, as shown in Figure 1. 


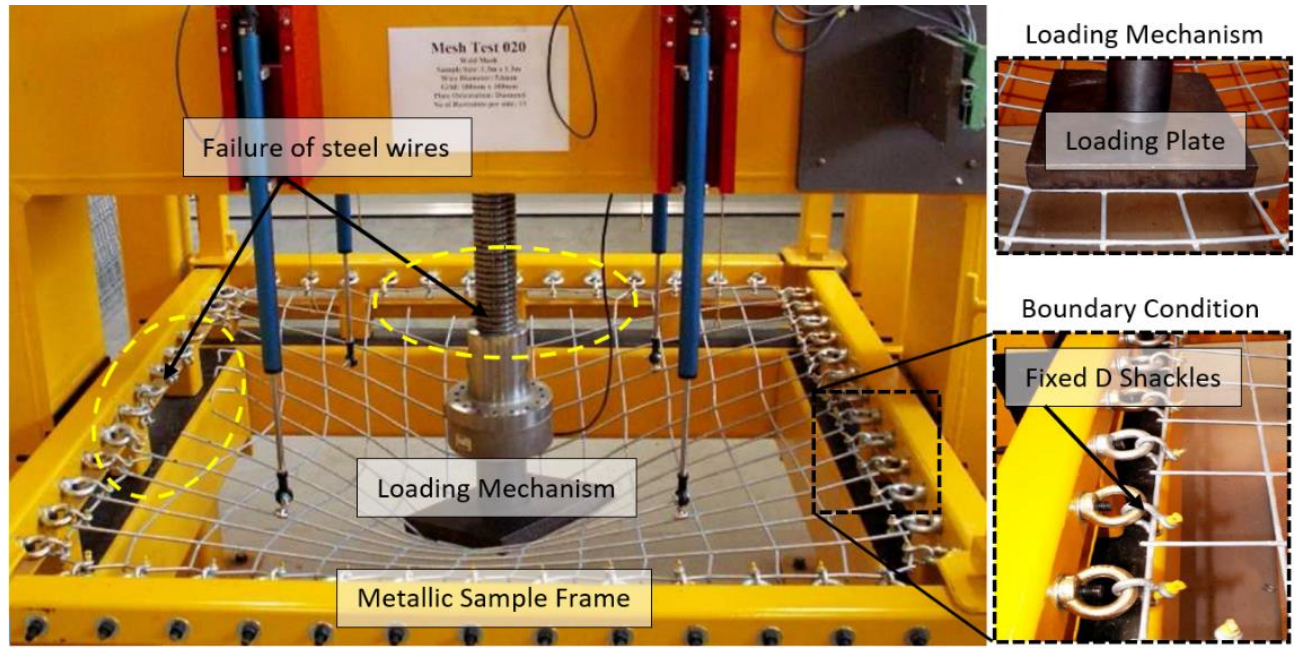

Figure 1 The Western Australian School of Mines testing rig and the examined test configuration (after Morton 2009)

\subsection{D DEM}

A 3D DEM software package, 3DEC from Itasca Consulting Group Inc. (2016a), was used in this investigation. In particular, the beam structural elements were used to represent the mesh. These elements can simulate support placed on exposed surfaces and allow bending and yielding. The assumption is that beam elements are straight segments of uniform properties lying between two nodal points and the mass of each segment is lumped at the nodal points. The generated forces are applied to the lumped masses which move in response to unbalanced forces and moments in accordance with the equations of motion. The axial stiffness is a function of the cross-sectional area and the Young's modulus of the steel. The elements can yield by assigning a tensile yield strength, and fail when a specified strain limit is reached. The advantage in the use of these elements is that they can take into account the bending resistance of the structural element. Slippage at the contact between the elements and the blocks is modelled in the same manner as the block interaction along a discontinuity (Itasca Consulting Group Inc. 2016b). The elements can slip along the blocks following a Mohr-Coulomb slip model (Itasca Consulting Group Inc. 2016b).

Figure 2 shows the configuration of the constructed numerical model to emulate the laboratory test set-up presented in Section 4.1. The welded steel wire mesh is modelled explicitly as an assembly of beam elements. The blocks at the boundaries of the model represent the metallic frame of the test rig and the $D$ shackle boundary condition explicitly. The loading plate is simulated by a block in the centre of the model and the load is applied to the beam elements through a velocity boundary condition in the $z$ direction.

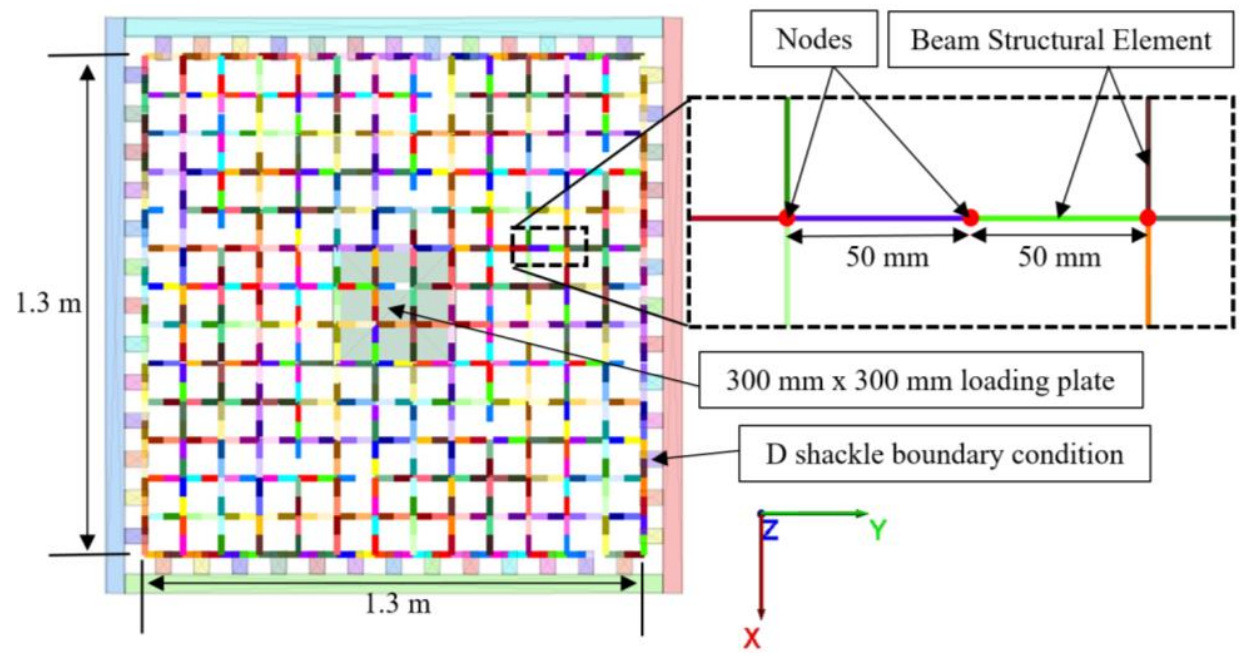

Figure 2 Numerical modelling geometry of the DEM model 
The first part of the numerical investigation was aimed at reproducing the tensile failure mechanism, while keeping the weld points intact. The elastic material properties and density assigned to the blocks and the beam elements were based on the steel properties, and the moment of inertia of the elements was estimated based on a $5.6 \mathrm{~mm}$ steel wire diameter. The yield strength of the elements was $450 \mathrm{MPa}$, which was equal to the strength of the wire. As no slippage was assumed between the blocks and the beam elements, higher values were assigned to the plastic contact properties of the beam elements. The elastic contact properties and the strain limit assigned to the elements were arrived at following a series of numerical tests and iterations. The material properties in Table 1 are the results of a calibration process between the load-displacement curves from the laboratory and the numerical results.

Table 1 The material properties for the beam structural elements and the block properties used

\begin{tabular}{|c|c|c|c|}
\hline \multicolumn{2}{|c|}{ Beam structural elements properties } & \multicolumn{2}{|l|}{ Block properties } \\
\hline Young's modulus ( $\mathrm{Pa}$ ) & $2 \times 10^{11}$ & Density $\left(\mathrm{kg} / \mathrm{m}^{3}\right)$ & 8,050 \\
\hline Poisson's ratio & 0.3 & Bulk modulus ( $\mathrm{Pa}$ ) & $1.67 \times 10^{10}$ \\
\hline Density $\left(\mathrm{kg} / \mathrm{m}^{3}\right)$ & 8,050 & Shear modulus ( $\mathrm{Pa})$ & $7.69 \times 10^{9}$ \\
\hline Tensile yield force (kN) & 11.08 & & \\
\hline Cross-sectional area $\left(\mathrm{m}^{2}\right)$ & $2.46 \times 10^{-5}$ & & \\
\hline Moment of inertia $\left(\mathrm{m}^{4}\right)$ & $4.83 \times 10^{-11}$ & & \\
\hline Strain limit & 0.0023 & & \\
\hline \multicolumn{4}{|c|}{ Contact properties } \\
\hline Normal stiffness (Pa/m) & $6 \times 10^{6}$ & Joint normal stiffness $(\mathrm{Pa} / \mathrm{m})$ & $100 \times 10^{9}$ \\
\hline Shear stiffness $(\mathrm{Pa} / \mathrm{m})$ & $4 \times 10^{6}$ & Joint shear stiffness $(\mathrm{Pa} / \mathrm{m})$ & $10 \times 10^{9}$ \\
\hline Cohesive shear strength $(\mathrm{N} / \mathrm{m})$ & $7 \times 10^{20}$ & & \\
\hline Tensile strength (N/m) & $2 \times 10^{20}$ & & \\
\hline Friction angle (degrees) & 85 & & \\
\hline
\end{tabular}

Figure 3 provides a comparison between a typical load-displacement curve from a laboratory test, as presented in Figure 1 where the mesh failed in tension, and the modelled curve. The two curves are in good agreement up to an applied load of $45 \mathrm{kN}$, but the peak of the numerical load-displacement curve was higher.

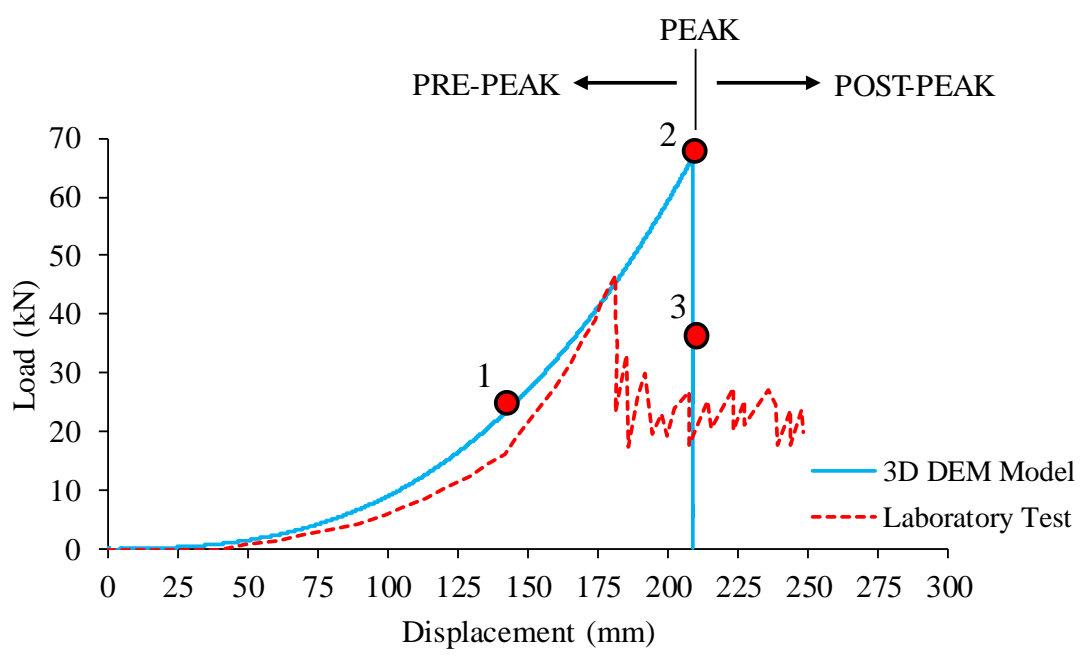

Figure 3 Modelled load-displacement curve using the 3D DEM and typical mesh performance in the laboratory 
The axial load and the vertical displacement (towards the $z$ direction) of the elements for different loading stages are shown in Figure 4. An algorithm was created to delete the beam elements when they exceeded the strain limit, to simulate explicit failure. The results indicate that the axial load on the elements increases with the applied load. The vertical displacement is larger in the middle of the model. At an applied load of $23.06 \mathrm{kN}$ (point 1 of load-displacement graph), there is higher axial loading in the elements that are directly under the loading block. At the peak of the load-displacement curve (point 2), the excessive load on the elements results in a tensile failure near the loading block. Beyond this threshold, the elements continue to fail around the loading block as illustrated at point 3.

1) Applied load: $23.06 \mathrm{kN}$, displacement: $141.27 \mathrm{~mm}$
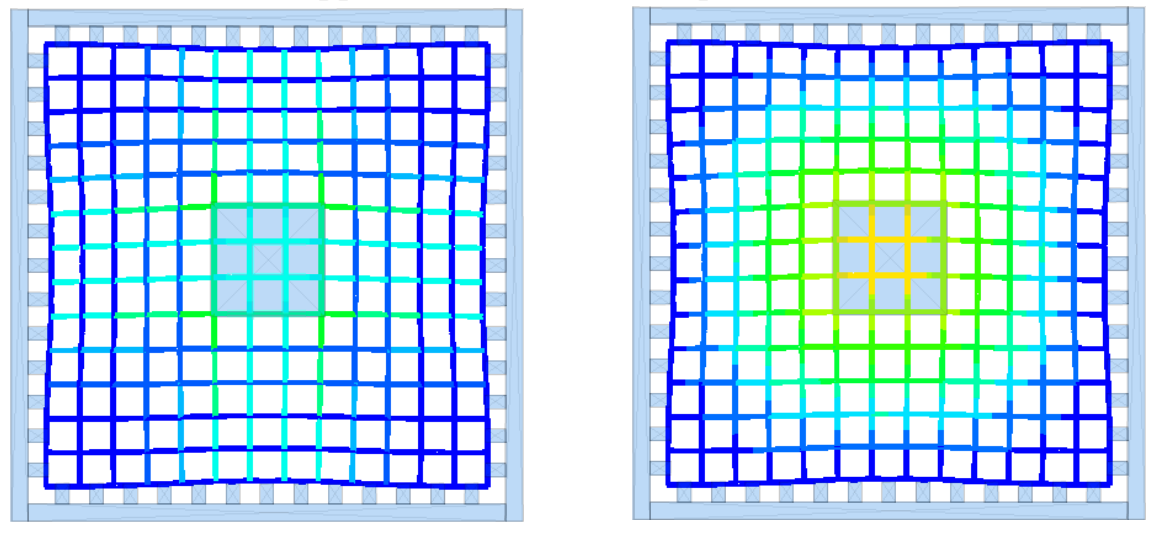

2) Applied load: $66.84 \mathrm{kN}$, displacement: $208.78 \mathrm{~mm}$
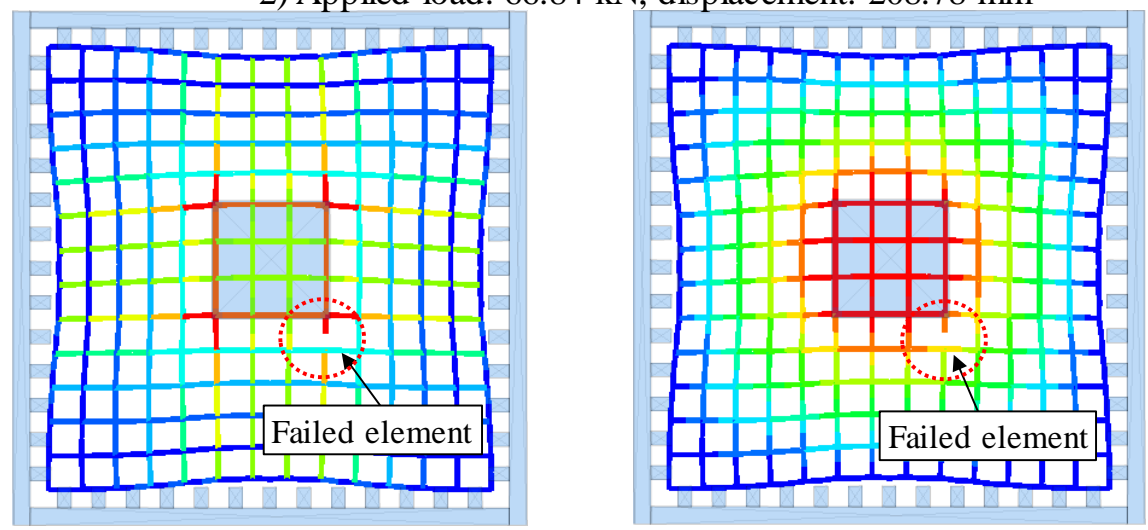

3) Applied load: $35.42 \mathrm{kN}$, displacement: $208.80 \mathrm{~mm}$

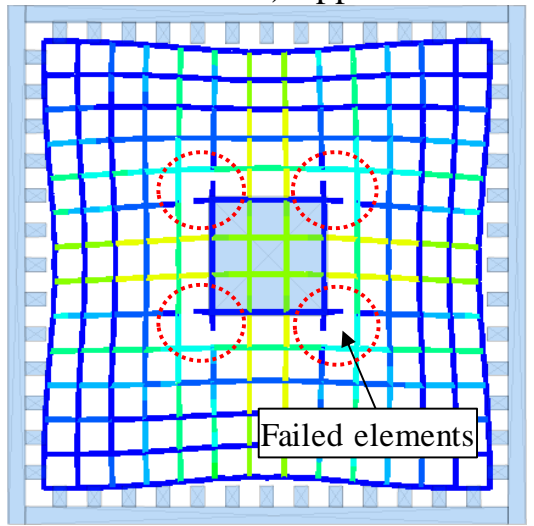

Beam elements, axial force $(\mathrm{N})$

$\begin{array}{lllll}0 & -3000 & -6000 & -9000 & -11084\end{array}$

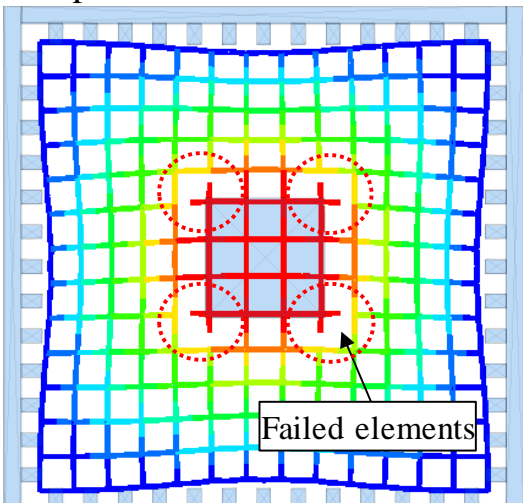

Beam elements, vertical displacement (m) $\begin{array}{llllll}0 & 0.04 & 0.08 & 0.12 & 0.16 & 0.2\end{array}$

Figure 4 Axial load and vertical displacement of the beam elements at different loading stages 
In these numerical experiments, mesh failure was localised at the loading plate and not at the boundaries as observed in the laboratory tests. Consequently, further calibration was necessary to better capture the mechanical behaviour of the welded steel wire mesh and to reproduce the observed failure mechanism.

\section{$5 \quad$ Capturing the mechanical behaviour of the welded wire steel mesh in the 3D DEM model}

The beam elements in the 3D DEM model take into account the bending resistance of the steel wire but do not allow any inelastic bending. A series of numerical experiments was undertaken to better capture the mechanical behaviour of the steel wires in bending.

\subsection{Numerical calibration of the beam elements in bending}

The elements were calibrated to account for inelastic bending based on the simulation of a three-point bending test. In the case examined, a point load was applied to the centre of a $5.6 \mathrm{~mm}$ diameter, $100 \mathrm{~mm}$ long steel beam. The steel beam was represented by two $50 \mathrm{~mm}$ long beam elements, the same as in Section 4 . Figure 5 shows a schematic representation of the three-point bending experiment and the modelled geometry.
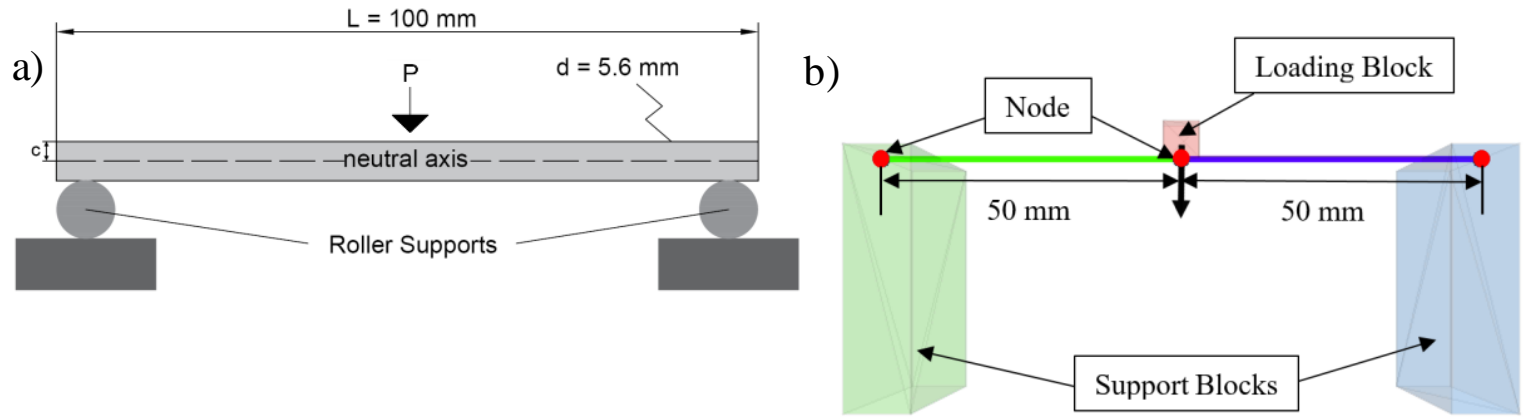

Figure 5 (a) Schematic representation of the three-point bending experiment; and, (b) Modelled geometry

The analytical solution for the three-point bend test was used to calibrate the elements. The bending stress $(\sigma)$ at the furthest distance away from the neutral axis at the mid-span of the beam is given by:

$$
\sigma=\frac{\mathrm{M} c}{\mathrm{I}}
$$

where:

$\mathrm{M}=$ the moment about the neutral axis at the mid-span.

c = the furthest distance from the neutral axis.

$I=$ the moment of inertia.

The maximum moment at the centre of the beam is given by:

$$
M=\frac{P L}{4}
$$

where:

$$
\begin{aligned}
& P \quad=\text { the point load applied to the beam. } \\
& L \quad=\text { the beam length. } \\
& d \quad=\text { the diameter. }
\end{aligned}
$$


The maximum deflection $(S)$ at the mid-span is given by:

$$
S=\frac{P L^{3}}{48 E I}
$$

where:

$E \quad=$ the Young's modulus of the steel (200 GPa).

For a tensile strength of $450 \mathrm{MPa}$, the moment at the centre of the beam based on Equation 1 is $7.8 \mathrm{Nm}$. The load applied to the beam when the tensile strength is reached, based on Equation 2, is $312 \mathrm{~N}$, and the maximum deflection based on Equation 3 is $0.7 \mathrm{~mm}$.

The experiment was reproduced in the numerical model. The load was applied to the node at the centre of the model by assigning a velocity boundary condition to a loading block towards the $z$ direction. Two rigid blocks were used with a zero velocity boundary condition to restrict the vertical movement of the two nodes at the edges. The material properties used for the beam elements and the blocks were the same as in Table 1. However, lower plastic properties were assigned to the beam node contacts to allow the nodes to slide along the blocks.

It was observed that the elements did not yield in bending. An algorithm was therefore developed to allow inelastic bending by setting a limit for the internal moment of the structural element segments of the beam elements. The bending moment limit assigned to the elements was the one derived from the analytical solution $(7.8 \mathrm{Nm})$.

Figure 6 illustrates the load-displacement response of the beam elements, the magnitude of the total bending moment at the node in the centre of the model, and the axial force of the beam elements at the different modelling stages. The graphs demonstrated that the elements yield at $312 \mathrm{~N}$ when the bending limit $(7.8 \mathrm{Nm})$ is reached. When the internal moment at the centre of the model reached the bending limit, the elements continued to bend without inducing additional resistance.
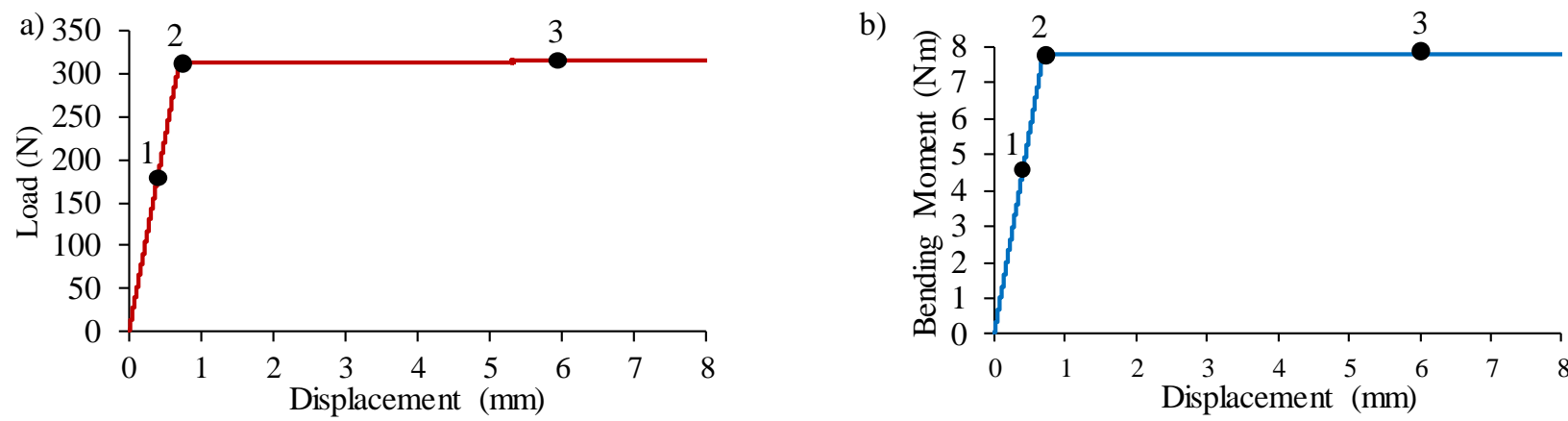

c)
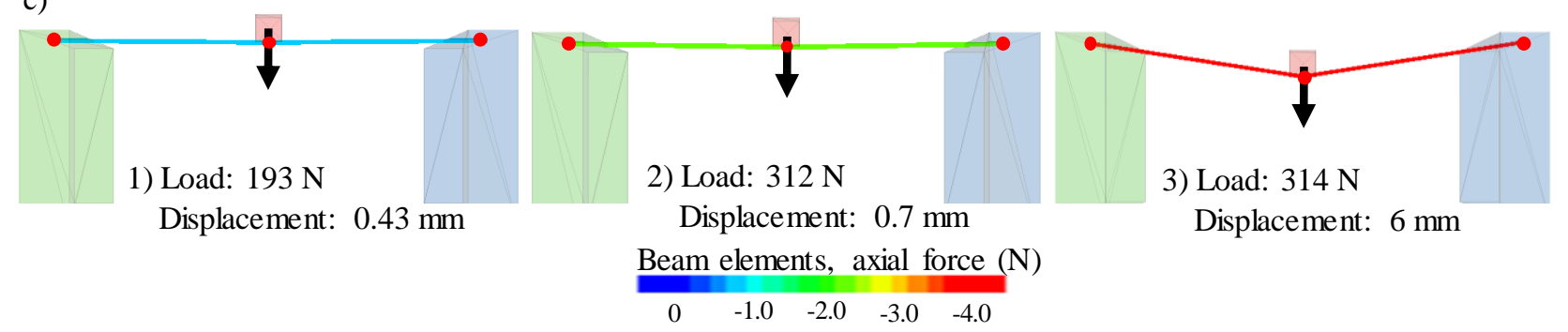
Displacement: $6 \mathrm{~mm}$

Figure 6 (a) Load-displacement curve for the modelled three-point load test; b) Magnitude of the bending moment at the central node; and, c) Modelled axial load on the beam elements for different magnitudes of the applied load

The numerical results for the yield load and the maximum deflection are in good agreement with the analytical solution. The axial load of the beam elements is minor as the elements are allowed to slide in the horizontal direction. The numerical results demonstrated that the beam elements were calibrated and can capture both the axial and bending behaviour of the mesh steel wires. 


\subsection{Application of the calibrated beam elements in the 3D DEM model}

The now calibrated beam elements were introduced to the 3D DEM model described in Section 4. A series of numerical iterations were necessary to fine-tune the selected strain limit and the elastic contact properties of the beam nodes. The material properties shown in Table 2 resulted in good agreement between the load-displacement response from the laboratory and the numerical modelling results as demonstrated in Figure 7.

Table 2 The calibrated material properties for the beam structural elements and the blocks

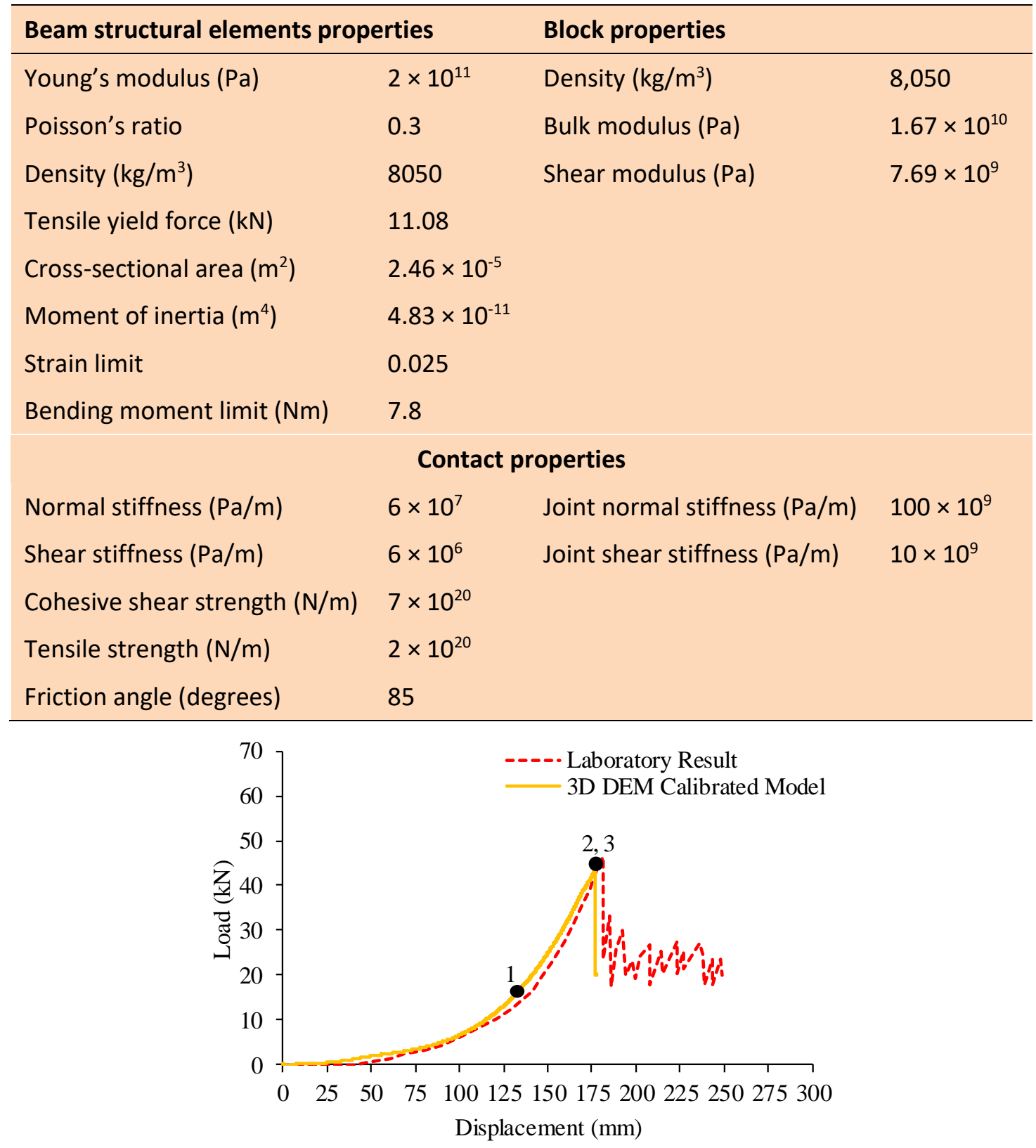

Figure 7 Load-displacement comparison diagram of the calibrated numerical model and the laboratory test result 
Figure 8 shows the axial load and the vertical displacement at different loading stages. The load is applied to the elements through the loading plate and is redistributed to the beam elements. For an applied load of $16.47 \mathrm{kN}$ (point 1 of the load-displacement curve), there was higher axial load at the wires that are directly loaded from the loading block. The elements at the boundaries of the model are subjected to a combined bending and axial load. As the beam elements bend, the load is concentrated at these areas. The elements eventually fail in tension at the boundaries as demonstrated at loading points 2 and 3 . After failure, there is a significant drop in the load-displacement curve. The numerical model captured the load redistribution and the failure mechanism observed in the laboratory tests.

1) Applied load: $16.47 \mathrm{kN}$, displacement: $133.55 \mathrm{~mm}$
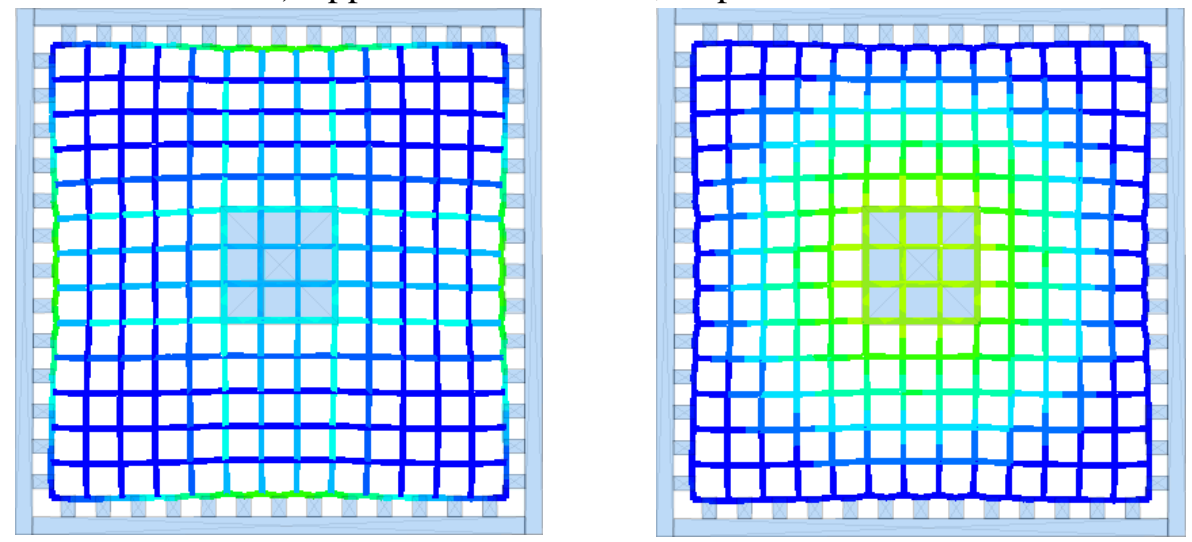

2) Applied load: $43.51 \mathrm{kN}$, displacement: $176.94 \mathrm{~mm}$
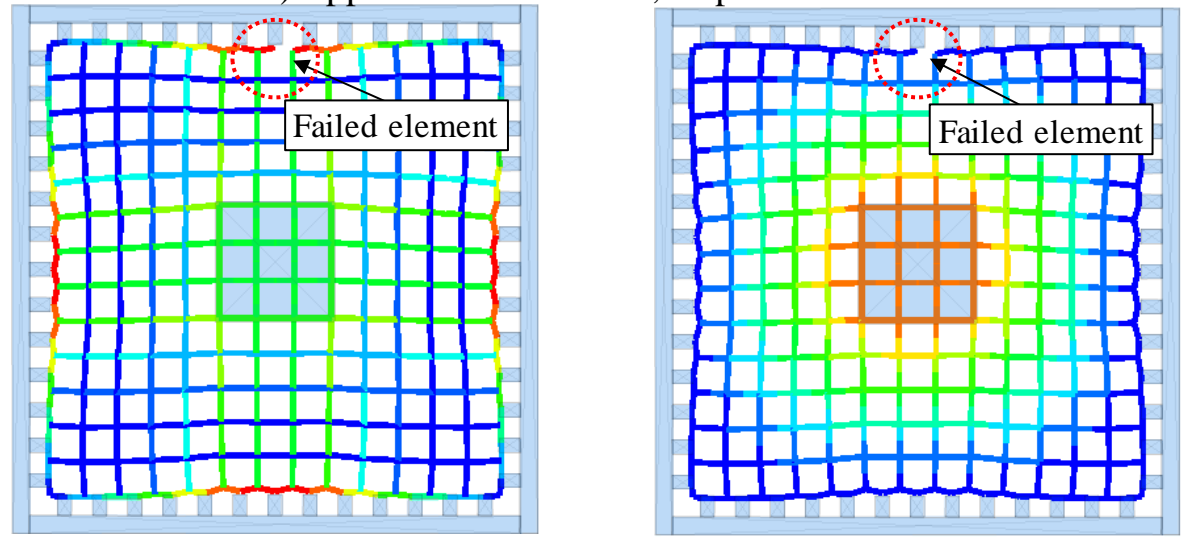

3) Applied load: $43.53 \mathrm{kN}$, displacement: $176.95 \mathrm{~mm}$

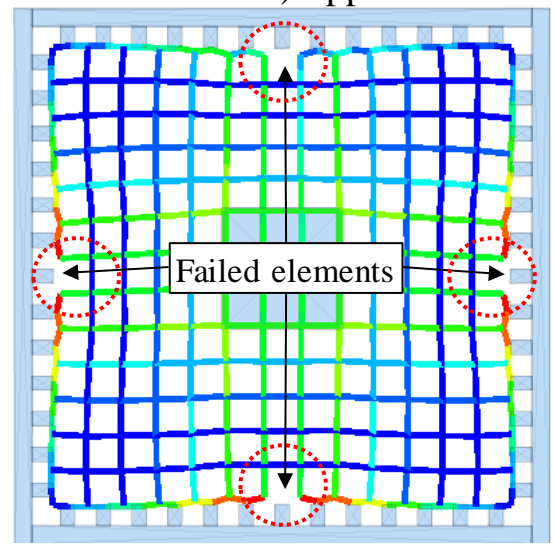

Beam elements, axial force $(\mathrm{N})$

$\begin{array}{lllll}0 & -3000 & -6000 & -9000 & -11084\end{array}$

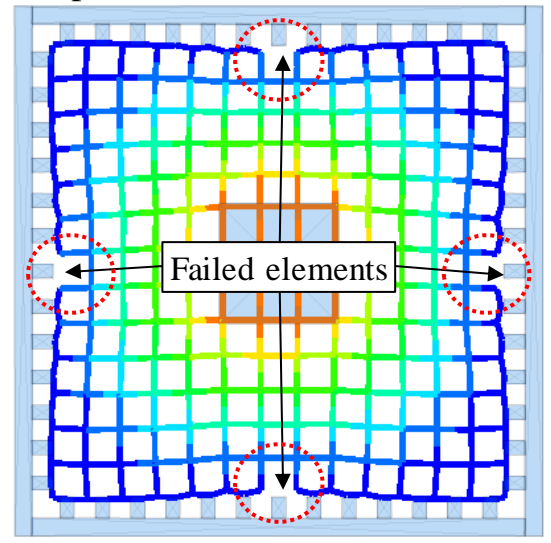

Beam elements, vertical displacement (m) $\begin{array}{llllll}0 & 0.04 & 0.08 & 0.12 & 0.16 & 0.2\end{array}$

Figure 8 Axial load and vertical displacement of the calibrated beam elements at different loading stages 
A further comparison between the observed laboratory loading mechanism of the steel wires and the modelling results is illustrated in Figure 9. In both cases, the load is initially transferred from the loading plate to the welded steel wire mesh along the directly loaded wires in area 1 (highlighted in red arrows). The load is subsequently transferred along the wires at the boundaries of the mesh (highlighted in blue arrows). As the load and the displacement increases, the wires become further tensioned and the load is transferred to area 2. The first failure of the wires occurs at the boundaries on one of the four directly loaded wires. The failure propagates to the other directly loaded wires and progresses to other periphery wires at the boundaries.

a)

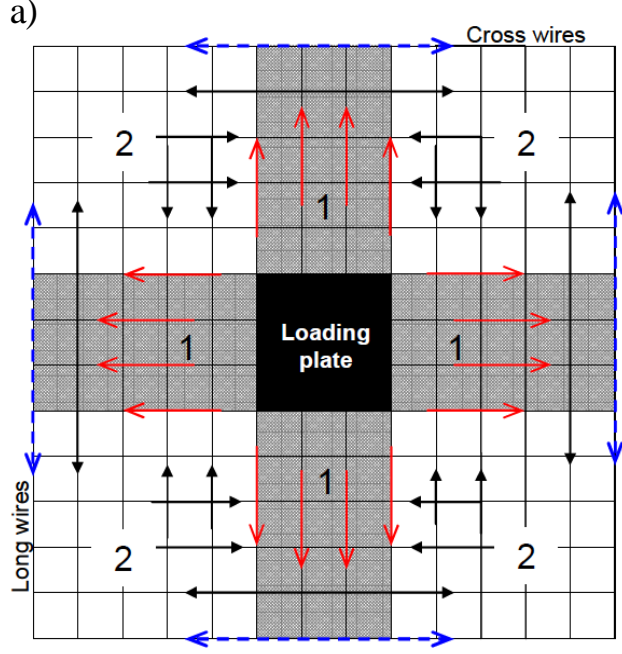

b)

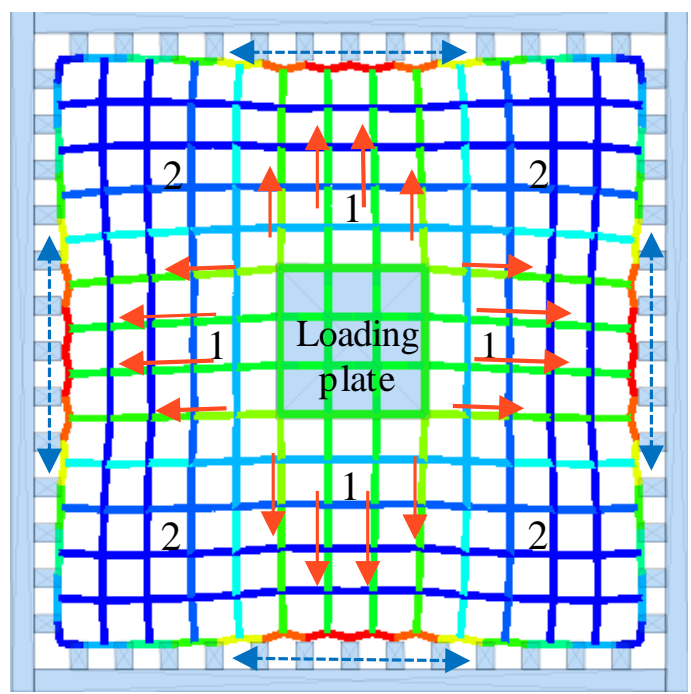

Beam elements, axial force $(\mathrm{N})$

Figure 9 Load transfer on the mesh steel wires; (a) Schematic representation of the observed load transfer in the laboratory (Morton 2009); and, (b) Modelled axial load on beam structural elements before failure

The laboratory test results showed a preferential failure location, limited to only two sides of the mesh, as shown in Figure 1. This was not captured in the numerical exercise which assumed an ideal symmetrical loading scenario. The preferential failure observed in the laboratory test can be due to an intrinsic defect associated with the mesh sample including the quality of welding, or a non-uniform boundary condition when the $D$ shackles are not placed in the middle of the wires.

\section{Conclusion}

The behaviour of steel mesh in laboratory tests is strongly influenced by the testing configuration. Laboratory tests on mesh can capture limited loading mechanisms and boundary conditions. The numerical modelling can provide significant insight into the parameters controlling the behaviour of mesh. As a first step, the 3D DEM was used successfully to capture the mechanical behaviour of mesh, as observed in laboratory tests using beam structural elements.

The model developed explicitly simulated the interaction between the mesh and the loading plate and captured the failure of the mesh explicitly. The modelling results indicated that there are numerous different parameters governing the performance of welded steel wire mesh. An algorithm was created to set a limit to the internal moments of the structural elements during bending. The numerical modelling results showed that the use of the bending moment limit was critical for capturing the mechanical behaviour of the mesh under the conditions examined. The elements reproduced the load transfer and the failure mechanism of the mesh steel wires as observed in the laboratory and simulated the failure explicitly. The resulting load-displacement response is in agreement with that reported in the laboratory tests. The numerical results provide confidence to proceed to the investigation of parameters controlling the behaviour of mesh, such as different loading conditions, using the calibrated model. 


\section{Acknowledgement}

The authors acknowledge the financial support of the Natural Science and Engineering Research Council of Canada. The technical input of Jim Hazzard of Itasca Consulting Group, Inc. is greatly acknowledged.

\section{References}

Barton, N, Lien, R \& Lunde, J 1974, 'Engineering classification of rock masses for design of tunnel support', Rock Mechanics and Rock Engineering, vol. 6, no. 4, pp. 189-236.

Bertrand, D, Nicot, F, Gotteland, P \& Lambert, S 2008, 'Discrete element method (DEM) numerical modelling of double-twisted hexagonal mesh', Canadian Geotechnical Journal, vol. 45, no. 8, pp. 1104-1117.

Coates, DF 1981, Rock Mechanics Principles, Mines Branch Monograph 874 (revised), CANMETEnergy, Department of Energy, Mines and Resources, Ottawa.

Dolinar, D 2006, 'Load capacity and stiffness characteristics of screen materials used for surface control in underground coal mines', Proceedings of the 25th International Conference on Ground Control in Mining, National Institute for Occupational Safety and Health, Washington, D.C., pp. 152-158.

Gadde, M, Rusnak, J \& Honse, J 2006, 'Behaviour of welded wire mesh used for skin control in underground coal mines', Proceedings of the 25th International Conference on Ground Control in Mining, National Institute for Occupational Safety and Health, pp. 142-151.

Grimstad, E \& Barton, N 1993, 'Updating the Q-system for NMT', in C Kompen, SL Opsahl \& SL Berg (eds), Proceedings of the International Symposium on Sprayed Concrete, Norwegian Concrete Association, Oslo.

Itasca Consulting Group Inc. 2012, FLAC3D — Fast Lagrangian Analysis of Continua, version 5.0, computer software, Itasca Consulting Group Inc., Minneapolis.

Itasca Consulting Group Inc. 2016a, 3DEC - Three-Dimensional Distinct Element Code, version 5.2, Itasca Consulting Group Inc., Minneapolis, https://www.itascacg.com/software/3dec

Itasca Consulting Group Inc. 2016b, 3DEC - Theory and Background, Itasca Consulting Group Inc., Minneapolis.

Lorig, L \& Varona, P 2013, 'Guidelines for numerical modelling of rock support for mines', in Y Potvin \& B Brady (eds), Proceedings of the Seventh International Symposium on Ground Support in Mining and Underground Construction, Australian Centre for Geomechanics, Perth, pp. 81-106.

Morton, E 2009, Static Testing of Large Scale Ground Support Panels, MSc thesis, Curtin University, Perth.

Morton, E, Thompson, A, Villaescusa, E \& Roth, A 2007, 'Testing and analysis of steel wire mesh for mining applications of rock surface support', in C Olalla, N Grossman \& L Ribeiro e Sousa (eds), Proceedings of the 11th Congress of the International Society for Rock Mechanics, Taylor \& Francis, London, pp. 1061-1064.

Ortlepp, W 1983, 'Considerations in the design of support for deep hard-rock tunnels', Proceedings of the 5th ISRM Congress, International Society for Rock Mechanics, Melbourne.

Potvin, Y \& Hadjigeorgiou, J 2016, 'Selection of ground support for mining drives based on the Q-System', in E Nordlund, TH Jones \& A Eitzenberger (eds), Proceedings of the 8th International Symposium on Ground Support in Mining and Underground Construction, Luleå University of Technology, Luleå, pp. 1-16.

Roth, A, Cala, M, Brändle, R \& Rorem, E 2014, 'Analysis and numerical modelling of dynamic ground support based on instrumented full scale tests', in M Hudyma \& Y Potvin (eds), Proceedings of the Seventh International Conference on Deep and High Stress Mining, Australian Centre for Geomechanics, Perth, pp. 151-164.

Shan, Z, Porter, I \& Nemcik, J 2014, 'Performance of full scale welded steel mesh for surface control in underground coal mines', in BI Morsi (ed.), Proceedings of the 31st Annual International Pittsburgh Coal Conference: Coal-Energy, Environment and Sustainable Development, vol. 1, International Pittsburgh Coal Conference, University of Pittsburgh, Pittsburgh, pp. 1-10.

Tannant, D 1995, 'Load capacity and stiffness of welded-wire mesh', Proceedings of the 48th Canadian Geotechnical Conference, Vancouver, pp. 729-736.

Thoeni, K, Giacomini, A, Lambert, C, Sloan, S \& Carter, J 2014, 'A 3D discrete element modelling approach for rockfall analysis with drapery systems', International Journal of Rock Mechanics and Mining Sciences, vol. 68, pp. 107-119.

Thompson, A, Windsor, C \& Cadby, G 1999, 'Performance assessment of mesh for ground control applications', in E Villaescusa, C Windsor \& E Thompson (eds), Rock Support and Reinforcement Practice in Mining, A.A. Balkema, Rotterdam, pp. 119-130. 